\title{
Removal of acid red 88 from wastewater by adsorption on agro- based waste material. A case study of Iranian golden Sesamum indicum hull
}

\author{
Mahmoud Zarei $^{{ }^{*}}$, Sakha Pezhhanfar ${ }^{1}$, Abolfazl Ahmadi Someh ${ }^{1}$ \\ ${ }^{1}$ Research Laboratory of Environmental Remediation, Department of Applied Chemistry, Faculty of Chemistry, University of Tabriz, \\ Tabriz, Iran
}

\begin{abstract}
Background: Colors are very useful in different industries such as textile and leather but when they enter water, can cause many biological and environmental problems. In the present research, a waste agricultural material which is freely available is employed to analyze its efficiency for removing acid dye from contaminated wastewaters.

Methods: In this study, batch adsorption experiments were performed in the treatment process of acid red 88 (AR88) by Iranian golden Sesamum indicum (IGSI) seeds hull which is produced abundantly in some countries and especially in Iran up to $1100 \mathrm{~kg} / \mathrm{ha}$. Also, the effect of operational parameters like adsorption time, $\mathrm{pH}$, dye concentration and adsorbent dosage was studied on pollutant removing efficiency. The experimental data of AR88 adsorption was fitted to Langmuir, Freundlich and Temkin isotherm models. The scanning electron microscopy (SEM) images for the IGSI were taken before and after adsorption process.

Results: The efficiency of dye adsorption on adsorbent was found to be $98.2 \%$. The optimum pH for treatment was 4.5 which is in the acidic range. Enhancing the adsorbent dosage from 0.5 to $2.5 \mathrm{~g}$ caused increasing in removal efficiency from $73.85 \%$ to $95.85 \%$. Decreasing in dye concentration from 70 to 30 $\mathrm{mg} / \mathrm{L}$ caused increasing in removal efficiency from $79.73 \%$ to $95.83 \%$. The process of adsorption was best fitted to Langmuir model and the amount of dye adsorbed on adsorbent, $\mathrm{q}_{\mathrm{e}}$, was found to be $25 \mathrm{mg} / \mathrm{g}$. Comparison between SEM images before and after dye adsorption, showed the significant difference that was due to the dye loading on adsorbent.

Conclusion: The results of present study demonstrated higher dye removal efficiency for AR88 in acidic pHs. Employing the IGSI material in this study proves to be a potential alternative to expensive adsorbents, utilized for the treatment of contaminated industrial waste waters.

Keywords: Adsorption, Acid red 88, Waste products, Sesamum, Waste water, Color removal

Citation: Zarei M, Pezhhanfar S, Ahmadi Someh A. Removal of acid red 88 from wastewater by adsorption on agro-based waste material. A case study of Iranian golden Sesamum indicum hull. Environmental Health Engineering and Management Journal 2017; 4(4): 195-201. doi: 10.15171/EHEM.2017.27.
\end{abstract}

Article History:

Received: 15 May 2017

Accepted: 11 July 2017

ePublished: 10 August 2017

\section{Introduction}

One of the most evident contaminants in water are colors and they come to water bodies from different sources such as textile and leather industries and from painting products in other industries. Color prevents light pervasion in water so decreases photosynthesis and disorder growing of biota. Because of composing chelate by metal ions produce micro-toxicity to fish and other organisms $(1,2)$. The release of azo dyes into the environment is a concern due to coloration of natural waters, toxicity, mutagenicity and carcinogenicity of these dyes and their bio-transformation products $(3,4)$. Some dyes under anaerobic conditions in wastewater, may decompose into carcinogenic aromatic amines and cause serious malady to men and animals $(5,6)$. Due to complex molecular structure, dyes are usually persistent against biodegradation, and thus it is difficult to eliminate them by natural aquatic environment $(7,8)$. And these poisonous materials absorb the oxygen of water $(9,10)$. The common decolorization methods for synthetic dyes are coagulation, flocculation, microbiological or enzymatic decomposition, adsorption, membrane filtration, ionexchange, oxidation and advanced oxidation (11). Because of the fact that every method has its own elimination, as an alternative, agricultural waste materials are inexpensive, freely available, abundant, having simple application, high efficiency and green chemistry. Then developing counties are eager to use them in order to treat industrial wastewaters (12-14). Many nonconventional, low-cost adsorbents such as jute stick powder (15), 
cattail root (16), Azadirachta indica leaf powder (17), jute processing wastes (18), peanut hull (19), orange peel (20), coir pith (21), bagasse pith (22), hardwood sawdust (23) and hazelnut shells (24) have been widely used for wastewater treatment in research areas. Harmless adsorption way by agricultural wastes, conducted us to use a novel adsorbent for removing pollutants from waste water. Thus, it is a good choice to remove synthetic dyes before they discharge downstream bodies of water. In this research, we studied the ability of Sesamum indicum seed's waste which is being produced annually in Iran, known as Iranian Golden Sesamum indicum (IGSI) for adsorption of acid red 88 (AR88) from simulated wastewater. $S$. indicum is a flowering plant in the genus Sesamum, also called benne. It is widely naturalized in tropical regions and Middle East countries and is cultivated for its edible seeds, which grow in pods or "buns". The world, harvests million tons of $S$. indicum seeds every year, and has many nutritional and nutraceutical properties $(25,26)$. S. indicum belongs to the family Pedaliaceae's which is estimated to have 36 species (24). But their wild species exist in Africa and a few in India (25). The origin of this plant is known in Ethiopia (27). Because of high nutritive quality and stability, $S$. indicum oil is known as a rich food (28). It has different usages and it clearly differs from other oils extracted from vegetables, because of its high nutritional and therapeutic values. The seeds of this species contain 50\%-60\% oil, $18 \%-25 \%$ protein, $13.5 \%$ carbohydrate and $5 \%$ ash (29). Sesamum has antioxidative, anticancer, antihypersensitive and anti-immunoregulatory actions (30). The considerable stability of the seeds to oxidation can be due to its endogenous antioxidant lignin along with tocopherols (29). S. indicum is a natural source of Calcium (approximately 1\%) and phosphorous (approximately $0.7 \%)(28)$. S. indicum contains plenty amounts of oleic (43\%), palmitic (11\%), stearic acid (7\%) and linoleic (35\%) which together include $96 \%$ of the total fatty acids (25). S. indicum seeds have different sizes and colors. They vary in size from small to large and are found in range of distinctive colors, depending upon the variety, including white, grey, black, golden and red (27). Especially in the eastern parts of the world, sesame has long been considered as a seed which provides high energy and prevents ageing (31).

Per capita production of this plant in Iran is doubled its world average production, equal to $1100 \mathrm{~kg} / \mathrm{ha}$. So it is available and inexpensive, and using its waste perfects its abilities (32). Finally the potential of IGSI as an agrobased waste material for removing the pollutant, AR88, by testing different parameters such as initial amount of adsorbent, $\mathrm{pH}$, initial dye concentration, adsorption time and studying the isotherm models was the aim of this study.

The results suggest a highly economical adsorbent for the removal of AR88 from wastewater. Additionally, this study helps to improve the removal efficiency of AR88 in comparison to other similar methods.
Materials and Methods

The preparation of the adsorbent (IGSI) and the adsorbate (AR88)

Sesamum indicum seed waste was collected as a solid waste which was obtained from a local oil-pressing shop in Tabriz. It was free of charge. Figure 1 shows the IGSI after being oil-pressed by its especial apparatus. The waste material was washed with distilled water for several times, and put in oven at $60^{\circ} \mathrm{C}$ for 4 hours. Then, the sample was ground completely with a mortar and pestle and then boiled for five times in distilled water to remove the residual oil and other unwanted materials and dirt particles. The washed material was dried in a hot air oven at $60^{\circ} \mathrm{C}$ for 48 hours. Then, the sample was ground completely again and the final sample was stored in an airtight plastic bottle for further use in room temperature. The dye used in this study was AR88 $\left(\mathrm{C}_{20} \mathrm{H}_{13} \mathrm{~N}_{2} \mathrm{NaO}_{4} \mathrm{~S}\right.$, molar mass $400.38 \mathrm{~g} / \mathrm{mol}$ ) which was obtained from Sigma-Aldrich corporation. The chemical structure of the dye is presented in Figure 2. As it was observed in UV-Vis spectrum (UV-Vis spectrophotometer, Jinan Hanon instruments, Model: i3) the maximum absorbance wavelength, $\lambda_{\max }$, was at $507 \mathrm{~nm}$. The stock solution (1000 $\mathrm{mg} / \mathrm{L}$ ) of AR88 was prepared by dissolving an accurate weight amount of dye in distilled water and the other concentrations were obtained by diluting this stock solution using the following formula:

$M_{1} V_{1}=M_{2} V_{2}$

The experiments were performed according to Khataee and Kasiri (33). $400 \mathrm{~mL}$ graduated cylinder containing $300 \mathrm{~mL}$ dye solution was utilized, in which the adsorbent was added. For more precision the experiments were done by two graduated cylinders containing equal amounts of adsorbent and dye concentration. UV-Vis results of both of them were obtained and the average was reported. Because of the fact that in present study the samples were taken every 5 minutes, and it had time delay to deposit the IGSI particles, the Graduated Cylinder was utilized in order to its height. Then the sampling of dye solution was easier and free from any adsorbent particles. The system was put on a magnetic stirrer (Hotplate \& Stirrer, JENWAY 1000) at a fixed stirring rate of $300 \mathrm{rpm}$. All

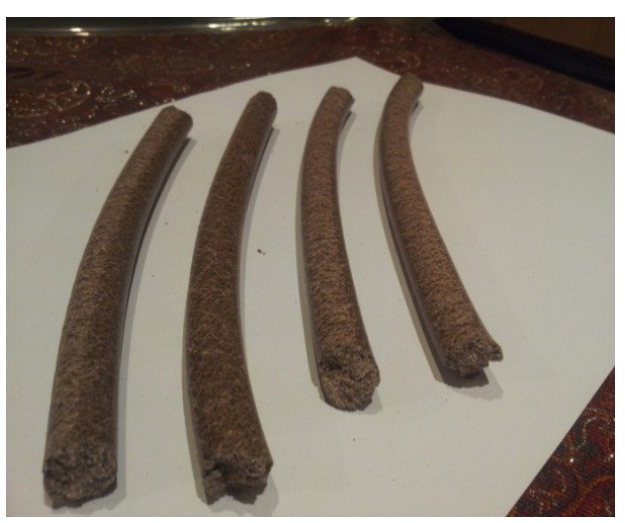

Figure 1. Sesamum indicum seeds after being oil-pressed. 
<smiles>O=S(=O)([O-])c1ccc(/N=N/c2c(O)ccc3ccccc23)c2ccccc12</smiles>

Figure 2. Chemical structure of acid red 88 .

the samples were centrifuged (Select-a-fuge 24 BIODYNAMICS) to deposit the trifle adsorbent. The rate of centrifuge was fixed on $5000 \mathrm{rpm}$ for 5 minutes. The batch removal experiments were carried out at different initial dye concentrations $(30-70 \mathrm{mg} / \mathrm{L})$, adsorbent weights $(0.5$ $2.5 \mathrm{~g})$, reaction time (5-170 minutes) and $\mathrm{pH}$ values (2.510.5 ), to evaluate the effects of operational variables on the dye removal efficiency. The desired $\mathrm{pH}$ was adjusted using $0.1 \mathrm{~mol} / \mathrm{L} \mathrm{HCl}$ and $0.1 \mathrm{~mol} / \mathrm{L} \mathrm{NaOH}$ by $\mathrm{pH}$ meter $(654 \mathrm{pH}$ meter Metrohm, Switzerland). At regular time intervals during adsorption process, 16 samples of the dye solution were totally taken, in each experiment and filled in test tubes which were put in test tube rack respectively. All the experiments were done at $\mathrm{T}=25^{\circ} \mathrm{C}$. Dye removal efficiency (\%) was expressed as the percentage ratio of decolorized dye concentration to that of the initial concentration as shown in the formula (33).

$\%$ Dye Removal $(D R \%)=\frac{C_{i}-C_{f}}{C_{i}} \times 100$

The amount of dye adsorbed at equilibrium $\mathrm{q}_{e}(\mathrm{mg} / \mathrm{g})$ was calculated by:

$q_{e}=C_{i}-C_{f} \times \frac{V}{M}$

where $C_{i}$ and $C_{f}$ are the initial and final liquid phase concentrations $(\mathrm{mg} / \mathrm{L})$. The volume of acid dye solution, $V$ in (L) and the adsorbent mass ( $\mathrm{g}$ ) is given by $M$. Scanning electron microscopy (SEM) (Sirion 200, FEI Co., Holland) was used to image the IGSI adsorbent before and after adsorption at a magnification of $\times 1000$.

Equilibrium adsorption isotherms are of fundamental importance in the design of adsorption systems. In this study, three isotherm models were selected to describe the adsorption of AR88 onto IGSI at $25^{\circ} \mathrm{C}$. These isotherm models include the Langmuir, Freundlich and Temkin models, and adsorption intensity $\mathrm{R}_{\mathrm{L}}$ (Eq. 4) was also selected to describe the adsorption.

$R_{L}=\frac{1}{1+K C .}$

The $R_{L}$ values indicate that the adsorption process is irreversible when $R_{L}$ is 0 , favorable when $R_{L}$ is between 0 and 1 , linear when $\mathrm{R}_{\mathrm{L}}$ is 1 and unfavorable when $\mathrm{R}_{\mathrm{L}}$ is greater than $1(34,35)$.

Results

Effects of operational parameters on adsorption process Effect of initial amount of adsorbent

In order to make a comparative study for adsorption of AR88 solution in the presence of different quantities of IGSI $(0.5-2.5 \mathrm{~g} / 0.3 \mathrm{~L})$, the initial concentration of AR88, reaction time and $\mathrm{pH}$ were kept constant. Figure 3 shows the effect of different weights of IGSI on adsorption of AR88 solution. It is clear that, dye removal significantly increased as the adsorbent weight increases.

Effect of initial dye concentration

Adsorption of dye on the adsorbent surface was determined for different concentrations of AR88 on $1.5 \mathrm{~g}$ of IGSI. According to the results, increasing the initial dye concentration, reduced the dye removal efficiency over the same time interval as shown in Figure 4.

\section{Effect of initial $\mathrm{pH}$}

The effects of $\mathrm{pH}$ on acid dye adsorption have been studied by many researchers, and the results indicated that, $\mathrm{pH}$ of solution could significantly influence the adsorption process $(36,37)$. Also in present experiment the effect of initial $\mathrm{pH}$ of solution was analyzed on adsorption efficiency. Hydrochloric acid was used to adjust the $\mathrm{pH}$ in lower levels and Sodium Hydroxide was utilized to adjust it in higher levels of $\mathrm{pH}$. Among $\mathrm{pH}$ ranges of dye solution (2.5-10.5) containing $50 \mathrm{mg} / \mathrm{L}$ dye, the adsorption efficiency was approximately significant in the $\mathrm{pH}=4.5$ as has been shown in Figure 5. The results indicated that the adsorption increases as the $\mathrm{pH}$ value is around acidic $\mathrm{pHs}$. According to the result of $\mathrm{pH}$ effects, we suggest the following mechanism for probable reaction between dye and adsorbent which is described in Figure 6.

The adsorption mechanism can be easily evaluated by determining the point of zero charge on adsorbent surface $(38,39)$. In this study the $\mathrm{pH}>\mathrm{pH}_{\mathrm{pzc}}$ helps to increase the adsorption of cations while the $\mathrm{pH}<\mathrm{pH}_{\mathrm{pzc}}$ helps to

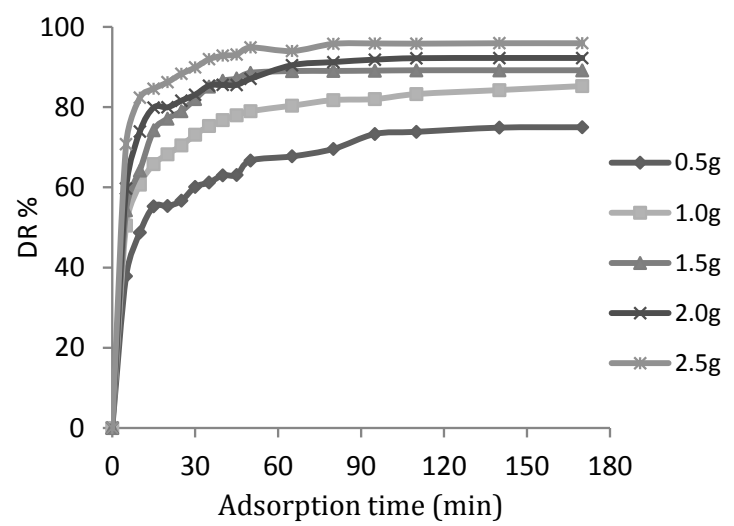

Figure 3. Effect of different IGSI weights on adsorption of AR88 $(\mathrm{pH}=6.5,[\mathrm{AR} 88] \mathrm{o}=50 \mathrm{mg} / \mathrm{L}$, reaction time $=170 \mathrm{~min})$. 
enhance the adsorption of anions. Solid addition method (40) was used to determine the point of zero charge of IGSI which was found to be 7 respectively. These are shown in Figure 7. In addition to mentioned experiments, another analysis was performed in order to find the effect of $\mathrm{pH}$ on dye solution which was free from any adsorbent. In this analysis the $\mathrm{pH}$ of pure dye solution was changed from 2.5 to 10.5. The results showed that there was no any sensible decolorization in $\mathrm{pH}$ range variation. Then by all these observations it is concluded, that the $\mathrm{pH}$ plays its role by effecting on adsorbent and causes different dye removal efficiencies in $\mathrm{pH}$ ranges (41).

\section{Effect of reaction time}

The effect of reaction time on dye removal efficiency was evaluated while the initial concentration of AR88, initial $\mathrm{pH}$ and IGSI weight were kept constant. Dye removal increased as reaction time was enhanced. Figures 3 and 4 also show the relation between reaction time and dye adsorption efficiency.

Surface characteristics of IGSI (before and after adsorption) The SEM images captured for the IGSI adsorbent before and after dye adsorption are respectively shown in Figures $8 \mathrm{~A}$ and $8 \mathrm{~B}$. Before pollutant adsorption, the IGSI had a surface which was rough with heterogeneous pores

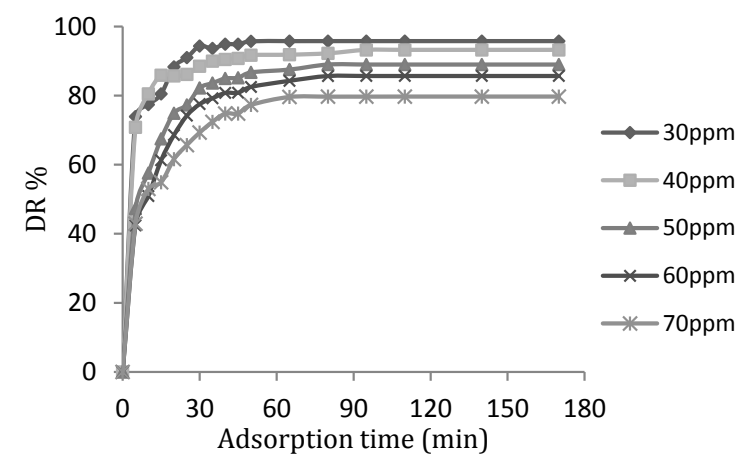

Figure 4. Effect of initial concentration of AR88 on removal efficiency $(\mathrm{pH}=6.5$, adsorbent weight $=1.5 \mathrm{~g}$, reaction time $=$ $170 \mathrm{~min}$ )

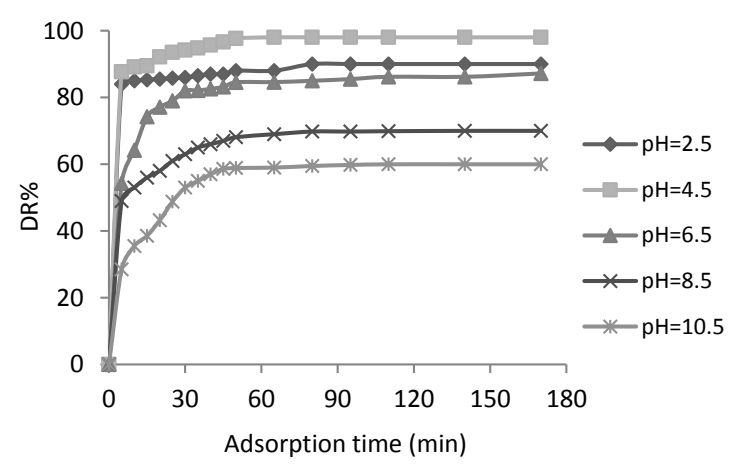

Figure 5. Effect of $\mathrm{pH}$ on adsorption of AR88 (adsorbent weight $=$ $1.5 \mathrm{~g},[\mathrm{AR} 88] \mathrm{o}=50 \mathrm{mg} / \mathrm{L}$, reaction time $=170 \mathrm{~min}$ ). and cavities, that indicated there was a good feasibility for AR88 to be trapped and adsorbed onto the surface. Because these pores and cavities supply a large exposed surface area. After adsorption, the surface of adsorbent was comparatively smoother, implying that AR88 molecules had become attached to the IGSI surface.

The equilibrium adsorption isotherms

In order to study the isotherm data for adsorption of AR88 onto the adsorbent, the Langmuir, Freundlich and Temkin models were analyzed and observed (42). Experimental results achieved for AR88 adsorbed onto IGSI at $25^{\circ} \mathrm{C}$ fit well to the three isotherm models. The equilibrium data were best represented by the Langmuir isotherm model and the plot between $\mathrm{C}_{e} / \mathrm{q}_{e}$ and $\mathrm{C}_{e}$ yielded a straight line with a high correlation coefficient $\left(\mathrm{R}^{2}=\right.$ 0.9842). The $R_{L}$ values for the adsorption of AR88 onto IGSI were in the range of $0.05-0.11$ when the initial AR88 concentration varied from 30 to $70 \mathrm{mg} / \mathrm{L}$. This indicates that the adsorption is a favorable process. The obtained parameters of mentioned isotherms, using the linear form of the isotherm equations are given in Table 1. The amount of dye adsorbed on adsorbent, $\mathrm{q}_{e}$, was found to be $25 \mathrm{mg} / \mathrm{g}$. The Freundlich isotherm constants were determined from the linear form of the model, and the values of $\mathrm{K}_{\mathrm{F}}, n$ and the correlation coefficient are given in Table 1. The Temkin isotherm constants for adsorption of AR88 onto IGSI calculated from the plot of $q_{e}$ vs $\ln C_{e}$ are

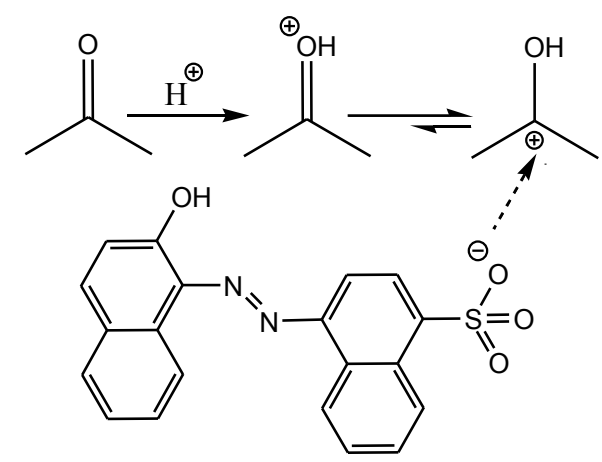

Figure 6. The schematic of suggested probable reaction between dye molecule and adsorbent surface.

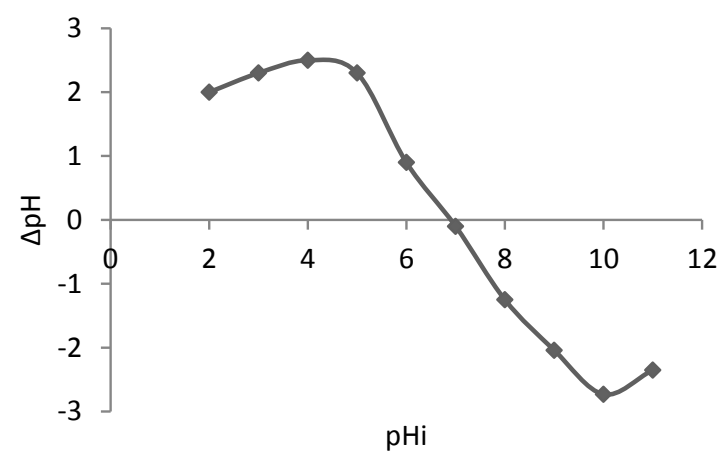

Figure 7. Point of zero charge of Sesamum indicum hull. 


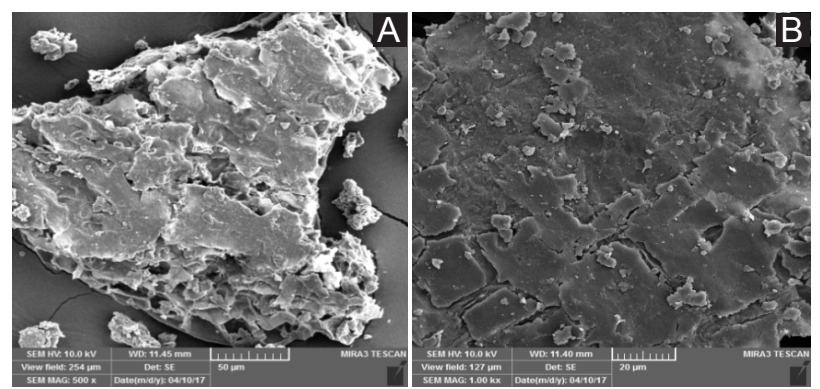

Figure 8. SEM micrograph of untreated $(A)$ and dye-loaded $(B)$ hull at the magnification of $\times 1000$.

given in Table 1 (42). The comparative fits of experimental data for adsorption of AR88, onto IGSI are shown in Figures 9, 10 and 11.

\section{Discussion}

Increasing the DR\% as enhancing the weight of adsorbent which is obvious in Figure 3, is because of the fact that increasing the amount of adsorbent provides more surface area for adsorption of dye molecules on the surface of $S$. indicum seed's hull (34). As the analysis around evaluation of the effect of dye concentration showed, increasing in concentration, resulted a reduction in removal efficiency. This can be due to the fact that there are only limited parts on the adsorbent surface to adsorb the dye, and as the concentration of AR88 is increasing, the chance of dye molecules for being adsorbed will be decreased (35). In $\mathrm{pH}$ analysis, the reason that influences the adsorption efficiency can be due to the fact that $S$. indicum hull contains hydroxyl groups as well as carbonyl groups, as determined using FTIR analysis (38). Therefore, the effect of $\mathrm{pH}$ on adsorption of AR88 onto IGSI might be attributed to electrostatic attractions. Electrostatic attractions may operate over a large range of $\mathrm{pH}$ (here from $\mathrm{pH} 2.5$ to $\mathrm{pH}$ 10.5) (39). At low $\mathrm{pH}$ values, the excessive $\mathrm{H}^{+}$ions may enter in a reaction with carbonyl groups and a new positive part generates on oxygen. Due to the fact that the positive charge is not stable on oxygen, it absorbs the bonding pair electrons and neutralizes. The conjugate carbon changes into a carbocation. This positively charged carbon, is now ready to be attacked by the anionic site of the dye. As the schematic of probable reaction was described in Figure 5. The point of zero charge showed that the adsorption capacity of $S$. indicum hull was enhanced by decreasing the $\mathrm{pH}$ of solution below $\mathrm{pH}_{\mathrm{pzc}}$. The reason might be the protonation of surface functional groups of adsorbent at low $\mathrm{pH}$ so more electrostatic interactions were developed between these protonated functional groups and dye anions. While negative charge on the surface of adsorbent was increased by enhancing $\mathrm{pH}$ above $\mathrm{pH}_{\mathrm{pzc}}$. So the adsorption efficiency was reduced by an increase in the $\mathrm{pH}$ on the alkaline side. Hereby the effect of $\mathrm{pH}$ on the adsorption of AR8 dye using IGSI at certain dose, $50 \mathrm{mg} / \mathrm{L}$ initial dye concentration and constant adsorption time was investigated. IGSI showed the maximum adsorption efficiency for AR88 dye in $\mathrm{pH} 4.5$.
Table 1. Isotherm parameters for the adsorption of AR88 onto IGSI

\begin{tabular}{lcc}
\hline Isotherm model & Parameter & Quantity \\
\hline \multirow{3}{*}{ Langmuir } & $\mathrm{q}_{\max }$ & 25 \\
& $\mathrm{~B}$ & 0.26 \\
& $\mathrm{R}^{2}$ & 0.9842 \\
Freundlich & $\mathrm{K}_{\mathrm{f}}$ & 10.11 \\
& $\mathrm{n}$ & 4.30 \\
& $\mathrm{R}^{2}$ & 0.8747 \\
Tempkin & $\mathrm{B}$ & 4.03 \\
& $\mathrm{~K}$ & 8.08 \\
& $\mathrm{R}^{2}$ & 0.8841 \\
\hline
\end{tabular}

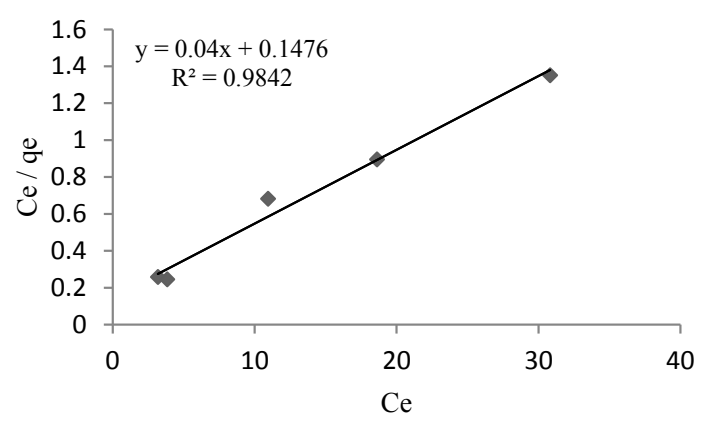

Figure 9. Fit of Langmuir isotherm data for the adsorption of AR88 onto IGSI.

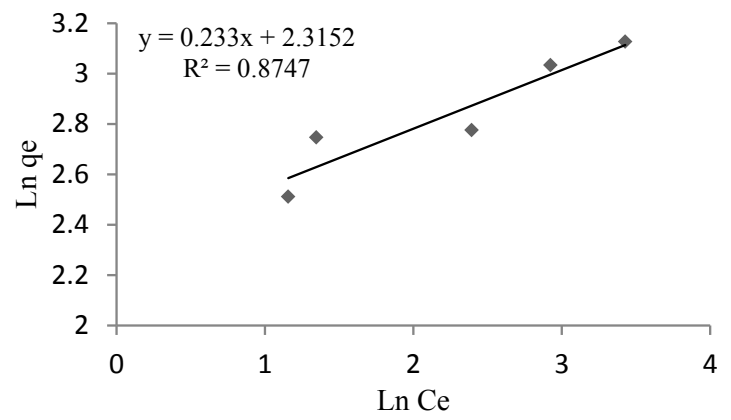

Figure 10. Fit of Freundlich isotherm data for the adsorption of AR88 onto IGSI.

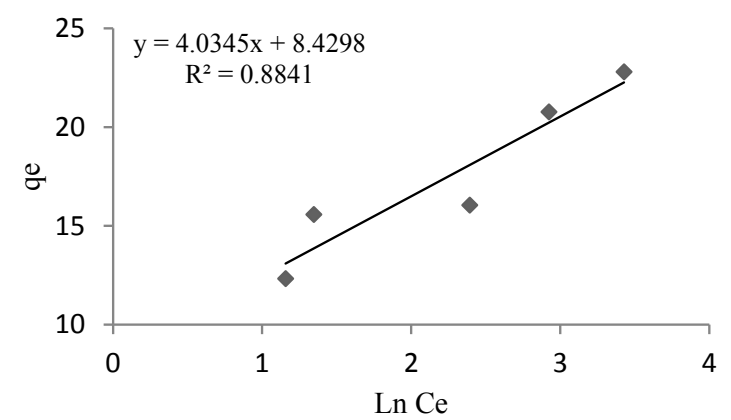

Figure 11. Fit of Tempkin isotherm data for the adsorption of AR88 onto IGSI

The adsorption efficiency was reduced from $98.2 \%$ to $60 \%$ with increasing $\mathrm{pH}$ from 4.5 to 10.5 . The surface showed maximum electrostatic attraction for dye anions after 
attained the more positive charge at optimum $\mathrm{pH}$ (41). The relation between adsorption time and DR\% showed that as the reaction time increases, the removal efficiency is being enhanced. It is due to the fact that when dye molecules have more time in dealing with the adsorbent surface, they have more chance to be adsorbed by them. As the analysis indicated in mentioned situation of experiment, at first 60 minutes, dye removal from aqueous system is rapid. This is obvious from the slope of curves in Figures 3 and 4 . After 60 minutes the slope tends to zero. It can be due to the fact that in the prime of adsorption process, the adsorbent has many sites to adsorb the dye molecules, but as the dye employs the parts on adsorbent surface, it becomes limited and a competition starts between molecules to be adsorbed by the adsorbent. The equilibrium data were best represented by the Langmuir isotherm model. According to the assumption of the Langmuir isotherm model, the adsorption of AR88 onto adsorbent occurred as a monolayer on the surface (42).

\section{Conclusion}

According to this study, it is proved that S. indicum seed's hull as an agro-based waste adsorbent, can be effectively employed for the removal of dye stuff AR88 from wastewaters. This adsorbent is available freely, locally and it is economic oriented. Especially in Iran and some other countries, it is very economical to be used in order to wastewater treatment due to its high amount of agricultural production. Dye removal efficiency increased as the amount of adsorbent and reaction time enhanced. Furthermore decreasing in initial dye concentration and $\mathrm{pH}$ caused increasing in adsorption efficiency. The isotherm data analysis proved monolayer sorption for acid dye. The SEM images for the IGSI before adsorption, showed pores and cavities which became smoother after being dye-loaded. Finally the ability of IGSI as a cheap and high efficiency adsorption source was proved and the contaminated water was refined up to $98 \%$ by the mentioned adsorbent.

\section{Acknowledgments}

The authors are thankful to University of Tabriz, Iran for all supports provided. Also we are thankful to Professor H. Namazi from department of organic chemistry, faculty of chemistry, university of Tabriz, because of helpful comments.

\section{Competing interests}

The authors declare that they have no competing interests.

\section{Ethical issues}

There were no ethical issues in the preparation of present article.

\section{Authors' contributions}

Authors were participated in all aspects of this research work, like analysis, data collection, interpretation and manuscript approval.

\section{References}

1. McKay G, Otterburn MS, Sweeney AG. The removal of colour from effluent using various adsorbents-III. Silica: Rate processes. Water Res 1980; 14(1): 15-20. doi: 10.1016/0043-1354(80)90037-8.

2. Brown MA, De Vito SC. Predicting azo dye toxicity. Crit Rev Environ Sci Technol 1993; 23(3): 249-324. doi: 10.1080/10643389309388453.

3. Chen KC, Wu JY, Yang WB, Hwang SC. Evaluation of effective diffusion coefficient and intrinsic kinetic parameters on azo dye biodegradation using PVAimmobilized cell beads. Biotechnol Bioeng 2003; 83(7): 821-32. doi: 10.1002/bit.10730.

4. Kar A, Smith YR, Subramanian V. Improved photocatalytic degradation of textile dye using titanium dioxide nanotubes formed over titanium wires. Environ Sci Technol 2009; 43(9): 3260-5. doi: 10.1021/es8031049.

5. Mahmoodi NM, Arami M. Numerical finite volume modeling of dye decolorization using immobilized titania nanophotocatalysis. Chem Eng J 2009; 146(2): 189-93. doi: 10.1016/j.cej.2008.05.036.

6. Mohan N, Balasubramanian N, Ahmed Basha C. Electrochemical oxidation of textile wastewater and its reuse. J Hazard Mater 2007; 147(1-2): 644-51. doi: 10.1016/j. jhazmat.2007.01.063.

7. Pandey A, Singh P, Iyengar L. Bacterial decolorization and degradation of azo dyes. Int Biodeterior Biodegradation 2007; 59(2): 73-84. doi: 10.1016/j.ibiod.2006.08.006.

8. Patil BN, Naik DB, Shrivastava VS. Photocatalytic degradation of hazardous Ponceau-S dye from industrial wastewater using nanosized niobium pentoxide with carbon. Desalination 2011; 269(1): 276-83. doi: 10.1016/j. desal.2010.11.014.

9. Phalakornkule C, Polgumhang S, Tongdaung W, Karakat B, Nuyut T. Electrocoagulation of blue reactive, red disperse and mixed dyes, and application in treating textile effluent. J Environ Manage 2010; 91(4): 918-26. doi: 10.1016/j. jenvman.2009.11.008.

10. Pirkarami A, Olya ME, Yousefi Limaee N. Decolorization of azo dyes by photo electro adsorption process using polyaniline coated electrode. Progress in Organic Coatings 2013; 76(4): 682-8. doi: 10.1016/j.porgcoat.2012.12.014.

11. Bayram E, Ayranci E. Electrochemically enhanced removal of polycyclic aromatic basic dyes from dilute aqueous solutions by activated carbon cloth electrodes. Environ Scie Technol 2010; 44(16): 6331-6. doi: 10.1021/es101177k.

12. Mondal S. Methods of Dye removal from dye house effluent-an overview. Environ Eng Sci 2008; 25(3): 38396. doi: 10.1089/ees.2007.0049.

13. Crini G. Non-conventional low-cost adsorbents for dye removal: a review. Bioresour Technol 2006; 97(9): 1061-85. doi: 10.1016/j.biortech.2005.05.001.

14. Bhatnagar A, Sillanpää M. Utilization of agro-industrial and municipal waste materials as potential adsorbents for water treatment-A review. Chem Eng J 2010; 157(2-3): 277-96. doi: 10.1016/j.cej.2010.01.007.

15. Demirbas A. Agricultural based activated carbons for the removal of dyes from aqueous solutions: a review. J Hazard Mater 2009; 167(1-3): 1-9. doi: 10.1016/j. jhazmat.2008.12.114.

16. Somasekhara Reddy MC. Utilization of agricultural wastes/ by-products in treatment of water and wastewater. In: Wealth From Waste. 2nd ed. New Delhi: TERI Press; 2005. 
17. Bhattacharyya KG, Sharma A. Azadirachta indica leaf powder as an effective biosorbent for dyes: a case study with aqueous Congo Red solutions. J Environ Manage 2004; 71(3): 217-29. doi: 10.1016/j.jenvman.2004.03.002.

18. Banerjee S, Dastidar MG. Use of jute processing wastes for treatment of wastewater contaminated with dye and other organics. Bioresour Technol 2005; 96(17): 1919-28. doi: 10.1016/j.biortech.2005.01.039.

19. Gong R, Ding Y, Li M, Yang C, Liu H, Sun Y. Utilization of powdered peanut hull as biosorbent for removal of anionic dyes from aqueous solution. Dyes Pigm 2005; 64(3): 18792. doi: 10.1016/j.dyepig.2004.05.005.

20. Namasivayam C, Muniasamy N, Gayatri K, Rani M, Ranganathan K. Removal of dyes from aqueous solutions by cellulosic waste orange peel. Bioresour Technol 1996; 57(1): 37-43. doi: 10.1016/0960-8524(96)00044-2.

21. Namasivayam C, Kadirvelu K. Coirpith, an agricultural waste by-product, for the treatment of dyeing wastewater. Bioresour Technol 1994; 48(1): 79-81. doi: 10.1016/09608524(94)90141-4.

22. McKay G, El Geundi M, Nassar MM. Pore diffusion during the adsorption of dyes onto bagasse pith. Process Saf Environ Prot 1996; 74(4): 277-88. doi: 10.1205/095758296528635.

23. Asfour HM, Nassar MM, Fadali OA, El-Geundi MS. Colour removal from textile effluents using hardwood sawdust as an absorbent. J Chem Technol Biotechnol 1985; 35(1): 2835. doi: 10.1002/jctb.5040350106.

24. Doğan M, Abak H, Alkan M. Biosorption of methylene blue from aqueous solutions by hazelnut shells: equilibrium, parameters and isotherms. Water Air Soil Pollut 2008; 192(1): 141-53. doi: 10.1007/s11270-008-9641-z.

25. Saydut A, Duz MZ, Kaya C, Kafadar AB, Hamamci C. Transesterified sesame (Sesamum indicum L.) seed oil as a biodiesel fuel. Bioresour Technol 2008; 99(14): 6656-60. doi: 10.1016/j.biortech.2007.11.063.

26. Hiremath SC, Patil CG, Patil KB, Nagasampige MH. Genetic diversity of seed lipid content and fatty acid composition in some species of Sesamum L. (Pedaliaceae). African Journal of Biotechnology 2007; 6(5): 539-43.

27. Bisht IS, Mahajan RK, Loknathan TR, Agrawal RC. Diversity in Indian sesame collection and stratification of germplasm accessions in different diversity groups. Genet Resour Crop Evol 1998; 45(4): 325-35. doi: 10.1023/A:1008652420477.

28. Nayar NM, Mehra KL. Sesame: Its uses, botany, cytogenetics, and origin. Economic Botany 1970; 24(1): 2031. doi: 10.1007/BF02860629.

29. Reshma MV, Balachandran C, Arumughan C, Sunderasan A, Sukumaran D, Thomas S, et al. Extraction, separation and characterisation of sesame oil lignan for nutraceutical applications. Food Chem 2010; 120(4): 1041-6. doi: 10.1016/j.foodchem.2009.11.047.

30. Elleuch M, Besbes S, Roiseux O, Blecker C, Attia H. Quality characteristics of sesame seeds and by-products. Food Chem
2007; 103(2): 641-50. doi: 10.1016/j.foodchem.2006.09.008.

31. Yoshida H, Tanaka M, Tomiyama Y, Mizushina Y. Antioxidant distributions and triacylglycerol molecular species of sesame seeds (Sesamum indicum). J Am Oil Chem Soc 2007; 84(2): 165-72. doi: 10.1007/s11746-0061020-6.

32. Production of sesamum indicum in Iran. Available from: http://www.yjc.ir/fa/news/4648459. Accessed April 13, 2017.

33. Khataee AR, Kasiri MB. Modeling of biological water and wastewater treatment processes using artificial neural networks. CLEAN - Soil, Air, Water 2011; 39(8): 742-9. doi: 10.1002/clen.201000234.

34. Khandare RV, Kabra AN, Kurade MB, Govindwar SP. Phytoremediation potential of Portulaca grandiflora Hook. (Moss-Rose) in degrading a sulfonated diazo reactive dye Navy Blue HE2R (Reactive Blue 172). Bioresour Technol 2011; 102(12): 6774-7. doi: 10.1016/j.biortech.2011.03.094.

35. Zarei M, Salari D, Niaei A, Khataee A. Peroxi-coagulation degradation of C.I. Basic Yellow 2 based on carbonPTFE and carbon nanotube-PTFE electrodes as cathode. Electrochimica Acta 2009; 54(26): 6651-60. doi: 10.1016/j. electacta.2009.06.060.

36. Atar N, Olgun A. Removal of acid blue 062 on aqueous solution using calcinated colemanite ore waste. J Hazard Mater 2007; 146(1-2): 171-9. doi: 10.1016/j. jhazmat.2006.12.002.

37. Saleem M, Pirzada T, Qadeer R. Sorption of acid violet 17 and direct red 80 dyes on cotton fiber from aqueous solutions. Colloids Surf A Physicochem Eng Asp 2007; 292(2): 246-50. doi: 10.1016/j.colsurfa.2006.06.035.

38. Feng Y, Yang F, Wang Y, Ma L, Wu Y, Kerr PG, et al. Basic dye adsorption onto an agro-based waste material - Sesame hull (Sesamum indicum L.). Bioresour Technol 2011; 102(22): 10280-5. doi: 10.1016/j.biortech.2011.08.090.

39. Bhattacharyya KG, Sharma A. Kinetics and thermodynamics of Methylene Blue adsorption on Neem (Azadirachta indica) leaf powder. Dyes Pigm 2005; 65(1): 51-9. doi: 10.1016/j.dyepig.2004.06.016.

40. Dawood S, Sen TK. Removal of anionic dye Congo red from aqueous solution by raw pine and acid-treated pine cone powder as adsorbent: Equilibrium, thermodynamic, kinetics, mechanism and process design. Water Res 2012; 46(6): 1933-46. doi: 10.1016/j.watres.2012.01.009.

41. Esmaeli A, Jokar M, Kousha M, Daneshvar E, Zilouei $\mathrm{H}$, Karimi K. Acidic dye wastewater treatment onto a marine macroalga, Nizamuddina zanardini (Phylum: Ochrophyta). Chem Eng J 2013; 217: 329-36. doi: 10.1016/j. cej.2012.11.038.

42. Hameed BH, Din ATM, Ahmad AL. Adsorption of methylene blue onto bamboo-based activated carbon: Kinetics and equilibrium studies. J Hazard Mater 2007; 141(3): 819-25. doi: 10.1016/j.jhazmat.2006.07.049. 